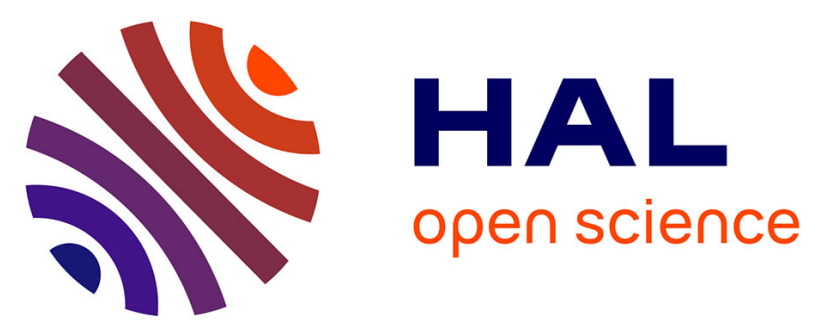

\title{
HOW ROBOTICS VISION AND COMPUTER VISION IMPROVE INTERDISCIPLINARITY
}

Jean-Paul Becar, Jean-Charles Canonne, Laurent Vermeiren, Abdelmalik Taleb-Ahmed

\section{- To cite this version:}

Jean-Paul Becar, Jean-Charles Canonne, Laurent Vermeiren, Abdelmalik Taleb-Ahmed. HOW ROBOTICS VISION AND COMPUTER VISION IMPROVE INTERDISCIPLINARITY. 10th International Conference on Education and New Learning Technologies, Jul 2018, Palma de Mallorca, Spain. 10.21125/edulearn.2018 . hal-02508946

\section{HAL Id: hal-02508946 \\ https://uphf.hal.science/hal-02508946}

Submitted on 16 Mar 2020

HAL is a multi-disciplinary open access archive for the deposit and dissemination of scientific research documents, whether they are published or not. The documents may come from teaching and research institutions in France or abroad, or from public or private research centers.
L'archive ouverte pluridisciplinaire HAL, est destinée au dépôt et à la diffusion de documents scientifiques de niveau recherche, publiés ou non, émanant des établissements d'enseignement et de recherche français ou étrangers, des laboratoires publics ou privés. 


\title{
HOW ROBOTICS VISION AND COMPUTER VISION IMPROVE INTERDISCIPLINARITY
}

\author{
Jean-Paul Bécar, Jean-Charles Canonne, Laurent Vermeiren, Abdelmalik Taleb \\ UVHC, IUT GEII Valenciennes (France)
}

\begin{abstract}
Since a decade, the academic syllabus for bachelors in Electrical Engineering domain is reserving a wide area for projects. The projects represent about ten percent of the final marks for the diploma validation after two years courses in theoretical, technical domains and its applications. The objectives are to make students more sensitive to the mixed knowledge, to manage a group rather rather giving academic lessons.
\end{abstract}

In any case, one success element of the project is laying on two facts always checked. First, the choice of the project by the students themselves and second the total availability of the teacher manager. Such an alike behaviour can be found in the purchase decision discussed by J. Dewey one hundred years ago meaning that good ideas are out of age.

Twenty years ago, the academic program of mathematics proposed to use a computer algebraic program in order to free all attendees from hard calculation. It was the starts of the DARE method still in use. It holds three major steps where the last step deals with the modelling of any electrical engineering problem. To be closer to the problem, mathematics authors had to discuss, adapt and share their teachings thus discover other teachings ways according to the concerned domain. That launched for years the collaborative work within sciences and applied sciences. The discussion mixing teachers of different domains in front of students make them pointing out the interest for the proposed subject. A showroom includes all current and past projects.

The first and ambitious project was to build a line tracker robot. Everything in electrical engineering from electronics to computer science and mathematics has been installed inside. The project took two years. Twelve students in bachelor of technology worked hard in order to compete in a place in the middle of France for a special challenge. The too sophisticated robot has been changed in another one based on Lego bricks offering more possibilities, easy programming languages and freeing the students of technical and time consuming aspects.

This has been used during many years and still now for projects, international projects and also for a one week devoted to open scholars to the sciences and the technology. In that background all staff members had been enrolled. The role played by the mathematics teachers was to organize, manage, check the results, refresh the motivation relayed by their colleagues.

Later and thank to a student idea, a new and sophisticated project got up as a bachelor of technology course was launched in the sustainable development with new equipment as solar panels, wind power and water station. The opportunity was to design an autonomous robot taking advantages of modern elements as micro controllers, microprocessors, cheap actuators and servo motors easy to program.

But a new direction for projects has been taken since five years. Based on a small, cheap and easy to program computer, it offers a tool for doing experiments at home in electronics, computer science and also mathematics and vision. Coming an attractive subject for students, the computer vision followed by the image processing is now rising in all minds. First in projects for a student coming from abroad to validate their practical course in engineering, the computer vision interest is growing up for local students. And second on a computer vision course designed to mix mathematics, computer science and image processing. The method is laying on the DARE method mentioned above.

Keywords: Robotics vision, computer vision, applied technology,

\section{INTRODUCTION}

The creation of Institute of Technologies in France was decided on sixties. The aim was to provide French companies with qualified employees specialized in fast developing technologies to bring help to engineers and companies in their efforts to modernization. The creation of Institutes of Technology was also a part of the territorial management. As Universities are only located in bigger towns, the 
creation of Institute of Technology in medium-sized cities is an opportunity to bring new technologies everywhere in the country to help local companies. It is also an opportunity to bring more young people to new jobs, in particular people from families with low income, who could not afford studies in bigger and more expansive towns. The Institute of Technology is one answer. (http://www.iutenligne.net/). The domain taught are directly in connection with companies activities. The Institute of technology delivers a University Diploma of Technology -DUT in French-. The diploma indicates a level of theoretical and practical skills in order to get a legal superior technician salary. The course takes two years after their baccalaureate. Some students are going on for a one year specialization in a bachelor of technology course. The best of them are changing their career path while going on in an engineer school.

Here, the specialty is the electrical engineering domain including elements of electronics, electrotechnics, control process, automation, local area network. According to their academic syllabus and in order to foster initiative, a large part of course is devoted to projects. The projects represent about ten percent of the final marks for the diploma validation after two years courses in theoretical, technical domains and its applications. The objectives for teachers are to make students more sensitive to the mixed knowledge, to manage a group rather giving academic lessons. In any case, one success element of the project is laying on two facts always checked. First, the students define themselves the project to be completed. Such a behaviour can be found in the purchase decision discussed by J. Dewey one hundred years ago meaning that good ideas are out of age $[1,2]$. Second the availability of the teacher manager feeds the wheel of constant improvement.

The running technology makes any syllabus difficult to match with it in a short delay. For future technicians, if the theoretical lessons are unavoidable, they must know what is new in their domain. A free pedagogical space is offered by projects. Here the authors are teachers-researchers in maths, computer science, control process and computer vision. They have participated in many activities mixing all the cited domains. Among these, the robots are taking a wide place. The running technology where the devices, components and tools today will be totally outdated within five years is the thread of the article.

The second section deals with experiments and activities on robots from the design to the programming. It points out the different subjects treated inside projects in order to give example on how it is possible to adapt the applied sciences. The projects are offering a free space for boosting motivation both for teachers and students. As they are written in the syllabus, the basic ideas must be defined or created by stakeholders. The section is pointing out the subjects, the reasons, the organization of such projects always in order to apply all the technology learned in an academic and traditional way but also to show what a course is able to propose later to scholars or forthcoming bachelors. The section shows the different steps that lead the group to the computer vision treated in section three. In this section, the authors apply a method to do maths with pleasure to the computer vision domain. The section ends with an application example. The outcomes are given in the conclusion part.

\section{ROBOTICS VISION}

\subsection{A robotic competition}

At the end of the academic year, motivated students in electrical engineering and industrial data processing course take part in a national friendly robotic contest [3]. The contestants mainly have to design and program their own autonomous mobile robot for lane tracking. Here, a group of French and Finnish students performed tools for a forthcoming participation. One goal of this project was to make students more sensitive to embedded systems and their real-time applications to classical and fuzzy controllers techniques. Their supervisors applied a known management method both for teamwork and student's assessment. The far too ambitious project took two years to be completed and to have a participation of the robotic competition. For the first robot, everything was designed, realized and tested at the Electrical enginering department. The first prototype (Fig 1. Left) was built as a computer with a microprocessor, boards for energy, line tracking, motors drivers and memory saving. The second prototype (Fig 1. Right) has been simplified using a new technology of microprocessor including all devices in a small space. 


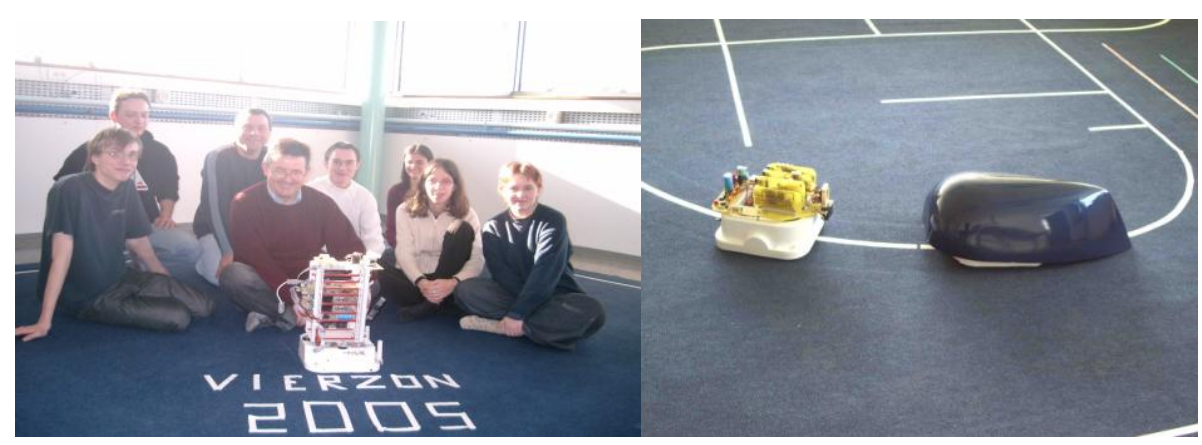

Fig 1: Two prototypes of a line tracker robot

The project has been let down for the needed time to set the equipment and software. The outcomes of these experiences were on how to manage a project taking account of the student motivation and his skills, the local available equipment, the new technology of and new supervisors joining this dynamic. For these reasons, the choice was fixed in a Lego system.

The two Lego bricks RCX (Fig 2. Left) and NXT(Fig 2. Right) propose a wide amount of possibilities depending only of the imagination. Since ten years, the department is using the robot Lego system for line tracker robots inside projects, for an international week robotics challenge with Irish, Finnish, Polish students and French apprentices $[4,5,6,7,8]$. This has been used also for an initiation to robotics programming with scholars during a yearly sciences fair week. During these years, the success of enterprise contributed to spread the motivation of students and teachers.

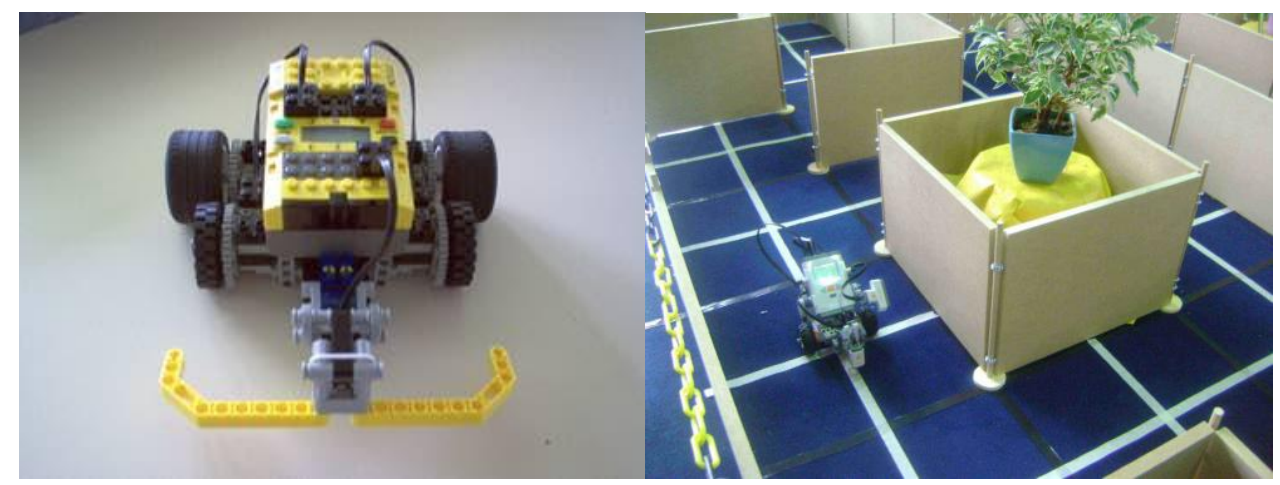

Fig 2: Lego Bricks RCX left, NXT Right

One example is coming from students themselves. A bachelor of technology in the sustainable development has been launched. Some students proposed to build a system including solar energy, energy saving and the electronics taught in the department. An autonomous robot was built and is still in use taking care of successive improvements $[9,10,11,12]$. Home designed and realized (Fig .3) the rover has been used for managing motors separately, installing solar panel with an algorithm giving at any the maximum power from light, moving the system with a joystick wire then wireless connected and now with a mobile telephone and later with a voice recognition process then a brain system connection.

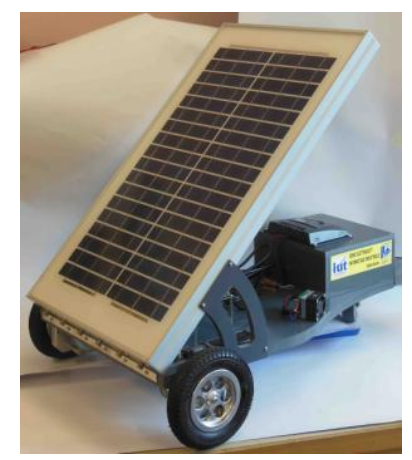

Fig 3: An autonomous rover equipped with a solar panel 
All projects above involved teachers-researchers with different specialities as Applied Mathematics, Electronics, Automation, Control process, computer science relayed by the technical resources of the department. Within ten years, the constant improvement provides excepted outcomes as detailed below.

\subsection{Impact factors}

The multidisciplinary working group and the knowledge shared in the group are the two main important outcomes. First, for students discovering a new way to applied the teachings and second hand for teachers going on for collaboration.

Working inside projects is also an example of learning by doing. The robot and their programming language make the sciences and technology more attractive and affordable to students and young. This has been mentioned every next year following the day where all future students are invited to discover the Institute of Technology, its equipment and its teachers and the completed projects. That gives a showcase of our savoir-faire and craft.

Suggested by students going abroad and teachers visiting partner University, the subject for project is moving lightly in the direction of the computer vision and its application.

\section{COMPUTER VISION}

\subsection{Motivation}

The main reasons why the authors have been motivated by the computer vision are given in the following:

1. Robot vision and recognition is getting an attractive domain.

2. Some projects of French students abroad are computer vision oriented as the recognition of letters and figures with a short delay for identifying the license tag of car crossing at red light, a study of face features in order to recognize members of a same family.

3. A low investment is needed to go on and experiment at home. For one hundred euros, one can be equipped of a cheap computer as Raspberry $\mathrm{Pi}$, a keyboard, display, mouse, webcam and open source software e.g. python and its library.

4. Foreign students in stay in France are choosing the computer vison project rather others.

5. Launched in projects for group of three French students working for 1 year, Japanese Indonesian and Vietnamese students for 1 or 2 months placement, the computer vision domain is spreading its interest now in academic courses. Thirty hours of theoretical and practical works on vision are planned in the syllabus.

The experience is organized using the pedagogical method DARE developed by the authors [13].

DARE is the acronym for Discover, Apply and Resolve. This method can be perceived as a rewriting, for computer languages, of the classical three-steps tests developed for language teaching: first translating from foreign language to native language, then translating from native language to foreign language and last writing an essay in foreign language.

The Discover step is devoted to translating computer language (here Python and OpenCV instruction) into native language. Student are given scripts they have to run and comment. In the Apply step student have to answer very simple questions using the instructions seen in the first step: they simply translate basic works into computer language. The last step Resolve is the most complicated but also most interesting step. Students must use their judgement, creativity and skills to solve a specific problem, in link with the previous steps.

\subsection{Writing a pedagogical sequence}

According to the previous experiences in the maths lessons with a computer algebra system, the authors apply the same method to start learning the domain of computer vision. The DARE method is recalled in the following. DARE is an acronym for Discover, Apply and Resolve. The method can be seen as rewriting for computer languages the classical three-steps tests used in any foreign language 
teaching. First step: translating from foreign language to native language. Second step: translating from native language to foreign language. Third step: writing an essay in the chosen foreign language. Here the so-called method takes the three following steps. D for Discovering that is here to launched program in computer vision, check the result, modify some parameters if any and write down comments, A for Applying meaning the path is to go from a simple application of the recent knowledge, and RE for resolving a short problem in less than two hours. The objectives are always to go one step forward and half a step backward. As a result of experimental psychology, the number of new items is fixed to eight at most.

An example on how to write a pedagogical sequence based on the method follows. A pedagogical sequence is generally written around a precise theme. Once the theme chosen, a specific problem in connection with the theme is defined. To avoid too much loss of generality, the "Object Tracking" problem will be chosen for this article as it can be linked to many themes.

The first thing to do when writing the subject of the sequence is to begin by the end, that is "Resolve the problem". A group of teachers solve the problem, compare their solutions and draw up a list of the different instructions used and check the feasibility in a fixed time. These instructions correspond to the different steps of the resolution of the problem: these steps will give the subjects of the different exercises of the "Apply" part. Once again teachers have to propose a list of exercises for each subject, solve them and then write scripts corresponding to solutions of similar exercises. These solutions give the "Resolve" part.

In the example below three main steps are distinguished. When doing "Object Tracking" with a camera, the first mathematical object encountered is the color RGB image.

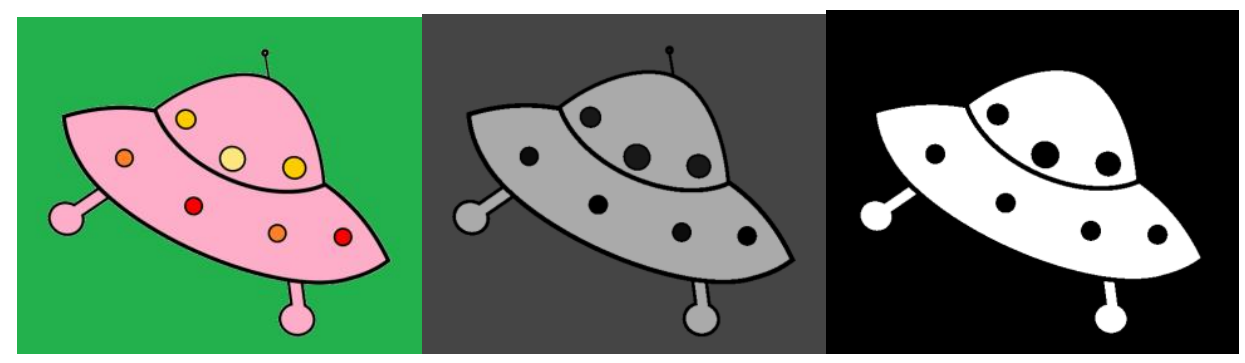

Fig 2: Left :Color Image; center : Greyscale Image (Hue component); right: Black and white image

Usually, this image is converted in the HSV-Hue Saturation Value- format which is a representation of the RGV color model. In both format a color image can be thought as three greyscale (or intensity) images. These greyscale images are thus transformed in black and white images using a threshold method. Finally the three main steps of the pedagogical sequence are designed: first Black and White images, then Greyscale images, and finally Color images.

\section{CONCLUSIONS}

Since twenty years, the authors are running after the vanishing motivation for mathematics. In many cases, specially inside multidisciplinary projects in robotics projects, they found new elements to restore the motivation. They have experimented learning by doing method, project based learning, Mooc sessions for computer sciences, robots programming and also computer vision. They found a method based on a computer algebra system that connects maths to technology through practical problems. This method is now applied in the computer vision domain. Their know-how and skills in that domain make the launch of a new course for the next academic called Bachelor of Technology course in the computer vision domain.

\section{ACKNOWLEDGEMENTS}

The authors warmly thank the Institute of Technology of the University of Valenciennes for helping and financing all mentioned projects. They also thank their colleagues and the staff members they facilitate the logistics. They alos thank their students for giving new ideas and new themes to study. 


\section{REFERENCES}

[1] J. Dewey, How we think, D.C, Heath and CO. Publishers, 1910.

[2] T. N. Martin, Smart Decisions: The Art of Strategic Thinking for the Decision-Making Process, New York, Palgrave Macmillan US, 2016

[3] J.-P. Bécar, L. Vermeiren, Design of an embedded system on a robot teaching platform, 7th IFAC Symposium on Advances in Control Education, Madrid, Spain, June 2006.

[4] L. Vermeiren, J.P Bécar., J.C Canonne, G. Longé, G. Lagache, L. Boidin, An example of initiation into research by means of a Lego system, IADAT -e2007, Proceedings of the $4^{\text {th }}$ IADAT International Conference on Education, Palma de Mallorca, Spain, July 2007.

[5] L. Vermeiren, J.P Bécar., J.C Canonne, G. Longé, G. Lagache, L. Boidin, A scientific advanced modelling project in a laboratory environnement, IADAT Journal of Advanced Technology on Education-IJAT-e, Volume 3, Number 2, September 2007., pp 369-371, ISSN 1698-1073.

[6] P.J. Gawthrop and E. McGookin, Using lego in control education. In S. Dormido, F. Morilla, and J. Sanchez, editors, 7th IFAC Symposium on Advances in Control Education, Madrid, June 2006.

[7] P.J. Gawthrop and E. McGookin, A lego-based control experiment. IEEE Control Systems Magazine, 24(5):43-56, October 2004.

[8] J.-C. Canonne, L. Vermeiren, E. Cartignies. , F. Robert, J.-P Bécar, Expériences d'initiation à la robotique en IUT GEII, Proceedings of the 9e Colloque Pédagogique Enseignement des Technologies et des Sciences de l'Information et des Systèmes CETSIS du 23 au 26 octobre 2011,Université du Québec àTrois-Rivières (Québec), Canada.

[9] J.-P. Bécar, E.Cartignies, J.-C.Canonne, L. Vermeiren, F. Robert, A multidisciplinary clientserver platform, IADAT - e2013 International Conference on Education 2013 Celebrating IADAT's 10th Anniversary Bilbao(SPAIN), July 18-20, 2013.

[10] A. Fratu, J.-P. Bécar, Robots Collision Avoidance Using Learning through Imitation, ISEEE2013 4th International Symposium on Electrical and Electronics Engineering (ISEEE) October 11-13, 2013 Galati, Romania IEEE Catalog Number CFP1393K-USB ISBN 978-1-4799-2441-7 Xplore Digital Library : http ://ieeexplore.ieee.org/xpl/mostRecentlssue.jsp ?punumber $=6662537$.

[11] A robotics experience with mooc, Jean-Charles Canonne, Jean-Paul Bécar, Aurel Fratu, Mariana Fratu, Iceri2015 proceedings, pp 6420-6425, 2015, ISBN: 978-84-608-2657-6.

[12] Are local teachers required within moocs sessions ?, Canonne J.-C., Bécar J.-P., Fratu A., Fratu M., proceedings of 10th International Technology, Education and Development Conference, Valencia, Spain. 7-9 March, 2016. ISBN : 978-84-608-5617-7 / ISSN : 2340-1079.

[13] J.-P., Bécar , F. Robert, J.-C. Canonne, L. Vermeiren, E. Cartignies, A method to connect mathematics and sciences using a computer algebra system, EDULEARN17 Proceedings ISBN: 978-84-608-8860-4, 9th annual International Conference on Education and New Learning Technologies, Barcelona (Spain). 3rd - 5th of July, 2017.

[14] P.I. Corke, Robotics, Vision \& Control, Springer 2011, ISBN 978-3-642-20143-1. 